\title{
EVALUATION OF SAFETY IN THE WORKPLACE IMPORTANCE IN A COMPANY FROM METAL PRODUCTS INDUSTRY
}

doi: $\quad 10.2478 /$ czoto-2019-0122

Date of submission of the article to the Editor: 12/11/2018

Date of acceptance of the article by the Editor: 15/01/2019

\author{
Krzysztof Mielczarek ${ }^{1}$ - orcid id: 0000-0003-3701-0192 \\ Radek Toman ${ }^{2}$ \\ ${ }^{1}$ Czestochowa University of Technology, Poland, krzysztof.mielczarek@wz.pcz.pl \\ ${ }^{2}$ Corp.CokeLab. AMO, a.s., Czech Republic
}

\begin{abstract}
The article presents research results in a scope of evaluation importance of safety in the workplace in the production processes of enterprise from metal products industry. Toyota's management principles by Jeffrey Liker were pointed out, which refers to elements of Toyota's house roof. An innovative BOST questionnaire survey was characterized as a tool for transformation of Toyota's management principles into questions. Research group which participated in BOST study from the metal product industry was characterized. Research results were subjected to statistical analysis with a use of basic statistical parameters. Research results showed that safety in the workplace is important factor in the company.
\end{abstract}

Keywords: safety in the workplace, BOST method, Toyota's house roof, importance hierarchy, statistical analysis

\section{INTRODUCTION}

In Toyota Motor Company (TMC) safety in the workplace has a special place, is one of production techniques of the company's excellence, integrated with the enlarging value process (Borkowski, 2016; Sobek et al., 1999). Survey and research method determined as BOST (the name of the is an acronym created from the first two letters of the name and surname of his creator i.e. Stanislaw Borkowski, professor of technical and economic sciences and the acronym is legally protected) was formed as a result of author's fascination in Toyota Motor Company (Gao and Low, 2015), in its management and production system, enhanced after reading a book by Jeffrey Liker "The Toyota Way: 14 Management Principles from the World's Greatest Manufacturer" (Amasaka, 2012; Liker and Franz, 2011).

BOST studies, full name is BOST study - Toyota's management principles in questions, were drawn up in order to assess in practice the approach to management in the Toyota Company amongst many manufacturing companies and service in Poland. BOST studies are aimed to prove that in enterprises operating in Poland, irrespective of conducted activity, the employees unconsciously use management principles, about which perhaps they never heard. 
Toyota's management principles in BOST method are described with some characteristic factors (Borkowski at al., 2013). A set of factors was called "areas". Toyota's management principles were divided into four sections, while the BOST questionnaire form has two versions: for employees and supervisors. BOST questionnaire form for the staff contains 20 questions and the version for managers 21 questions and 7 questions so-called "demographics".

\section{RESEARCH METHODOLOGY}

BOST questionnaire survey - Toyota's management principles in questions were conducted in enterprises from metal product industry. A preliminary condition for classification of the companies to BOST study was confirmed information about implementation of Toyota management principles in the workstations in analyzed company. In selected enterprise the population of respondents was chosen, which consisted from production workers of the examined enterprise, having a contact with manufacturing process in the workplace. Studies were marked by a low degree of anonymity, but with large degree of control by the interviewer. Applied questionnaire form - lecture and direct questionnaire - affected on increase in measurement control. It was an intentional treatment, which was supposed to contribute in increase of the correctness in filling surveys by pollsters (Knop and Mielczarek, 2018). The BOST questionnaire form was filled out, by 40 respondents i.e. more than half of production workers. This article presents an analysis of the answers given to the question contained in the BOST questionnaire, referring to the roof of Toyota's house (mission of enterprises) (Borkowski at al., 2014) Employees have answered the following question: "Which factor is the most important in your enterprise?" Fill in the blanks with $1 ; 2 ; 3 ; 4 ; 5$ (5 the most important factor).

\begin{tabular}{|c|l|l}
\hline JA & & Quality \\
\hline KO & & Cost \\
\hline CR & & Execution time \\
\hline BP & & Safety in the workplace \\
Attitude of the crew
\end{tabular}

\section{CHARACTERISTISC OF RESPONDENTS}

Majority of researched employees from examined are man, i.e. 55\%. The most, because up to $35 \%$ of respondents declared secondary education, $26 \%$ pointed on higher education. Respondents most often were aged "from 31 to 40 years" (37\%), and next in terms of aged: "up to 30 years" (25\%), "from 51 up to 55 years" (23\%). Most often indicated work experience was "from 11 to 15 years" (27\%). To question "your current employment is a place of employment": respondents most often pointed at the third place of employment (38\%) and majority of them, i.e. $52 \%$, was employed under "normal" procedures. Typical respondent - production worker of examined enterprise is: a man with secondary education, aged between 31-40 years, with work experience from 11 up to 15 years, for which current employment is the third place of employment, which in the current company was employed under normal condition (employment contract).

A profile of typical respondent was drawn up, i.e. a production worker of examined enterprises, as the best and worst assessing the importance level of the Safety in the workplace (BP) . Analysis results were presented in Fig. 1. 


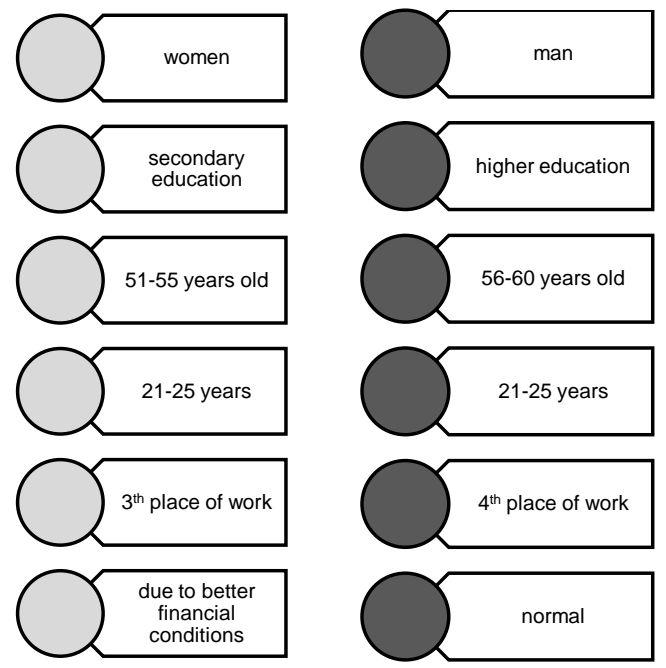

Fig. 1. Respondents' personal profiles the best and the worst evaluating the importance of the Safety in the workplace (BP) factor in the enterprise

A person who the best assessed the importance of subjective factor is: a woman with the secondary education, at the age of 51-55 years, with work experience from 21 to 25 years, which a current place of employment is the third, and which was employed in the company due to better financial conditions.

In turn, the worst assessing the importance of examined factor is: a man, with higher education, at the age of 56 up to 60 years, with work experience of 21 up to 25 years, which a current place is the fourth, and which was employed was employed under normal condition.

\section{CORRELATION}

Correlation, between two variables, is a measure of the connection occurring between these variables (Knop, 2018). Value most often assumes the strength of the interdependence of two variables from the range. It should be remembered, that value close to the zero not always mean a lack of the relation, but only a lack of the linear relation between variables. In Fig. 2 was presented correlation graphs for factors from E1 area depending on features of respondents.
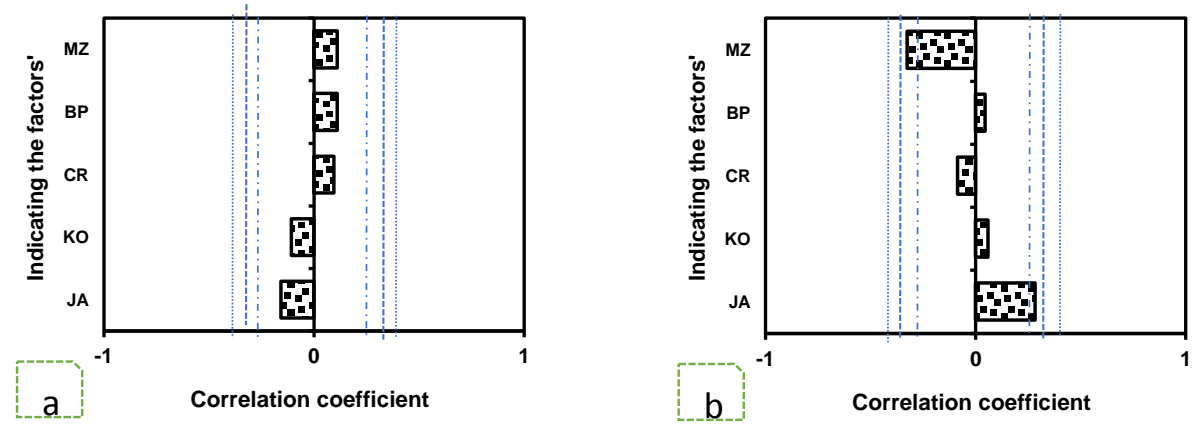

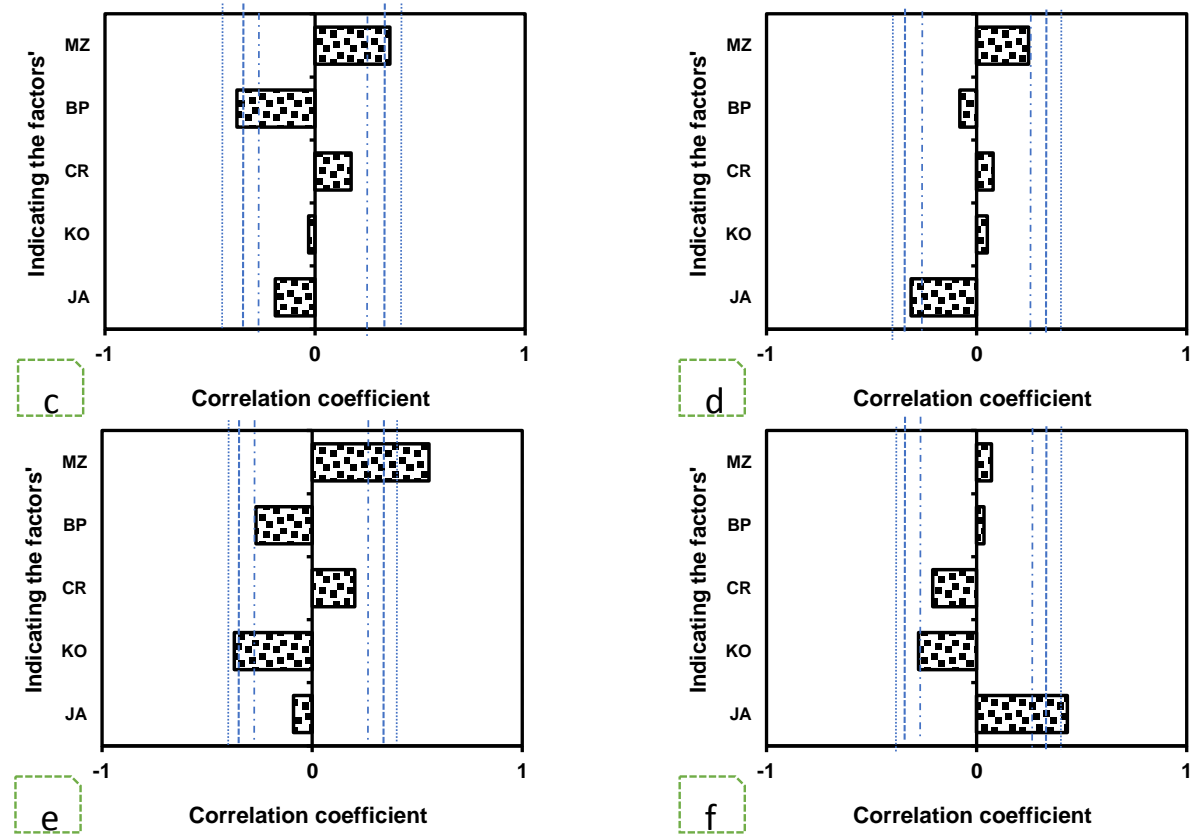

Fig. 2. Roof of the Toyota house. Correlation graphs of evaluations in E1 area depending on the respondents feature: a) gender, b) education, c) age, d) work experience, e) mobility, f) mode of the employment. $\alpha=0,2$ (internal lines), $\alpha=0,1$ (central lines), $\alpha=0,05$ (external lines)

Analyzing the correlation graph for E1 area depending on the respondents' gender (Fig. 1a), it is possible to notice that none of five factors demonstrated any the relation of levels of the significance $(\alpha=0.2 ; \alpha=0.1 ; \alpha=0.05)$ between results of the assessment and gender of respondents. From Fig. $2 b$ results, that two factors, that is the Quality (JA) and Attitude of the crew (MZ), demonstrated the relation between results of the assessment and educating respondents, both on the level $\alpha=0.2$, as well as $\alpha=0.1$. Together with the height of educating the assessment of the factor Attitude of the crew $(\mathrm{MZ})$ are decreasing. With the height of educating the assessment of the importance of the factor quality $(\mathrm{JA})$ is growing. Three remaining factors demonstrated the smaller correlation relationship what is providing about the fact that remaining elements will be realized in the way determined by procedures. Examining Fig. $2 \mathrm{c}$ it is possible to state, that two factors Attitude of the crew (MZ) and Safety in the workplace (BP) are demonstrating the relation between results of the assessment of the importance and the age of respondents, both on the level $\alpha=0.2$, as well as $\alpha=0.1$. In the case of the correlation graph for factors from E1 area depending on the work experience of respondents (Fig. 2d) two factors, i.e. Attitude of the crew (MZ) and Quality $(\mathrm{JA})$ are demonstrating the correlation relationship. Remaining factors are demonstrating the much smaller relation between results of the assessment and the work experience of the crew in the enterprise. In Fig. $2 \mathrm{e}$ it is possible to observe that three factors are demonstrating the relation between results of the assessment and the mobility of respondents on levels of the significance. It should be emphasize that correlation between the mobility and the assessment of the factor Attitude of the crew (MZ) exists even on the level $\alpha=0.05$. Together with the height of the number of places of employment of respondents morale of the crew is increasing. In the case of appearing of the relation between results of the assessment and the way of employing respondents on all levels, for two factors are demonstrating the relation - Costs (KO) 
and Quality (JA). Together with the change of the way of employment from normal for the job better paid, costs are decreasing, and the quality is growing.

\section{BUILDING IMPORTANCE SERIES FOR FACTORS OF ENTERPRISE MISSION}

For the individual evaluations of factors were built Pareto-Lorenz diagrams (Ulewicz et al., 2013). It was taken in terms of the assessment with taking into consideration value allotted to determined factors. Five diagrams were presented where every is showing the distribution of factors basing on the importance for researched area. Each diagram is presenting accumulated value of individual assessments from „1" to „5”.

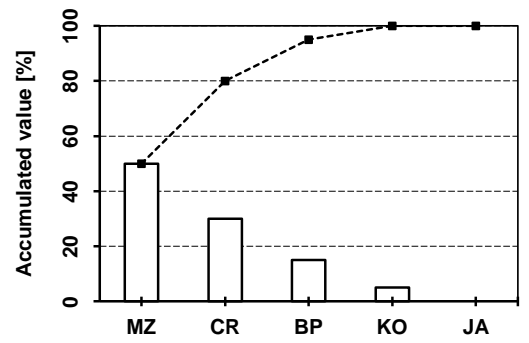

a)

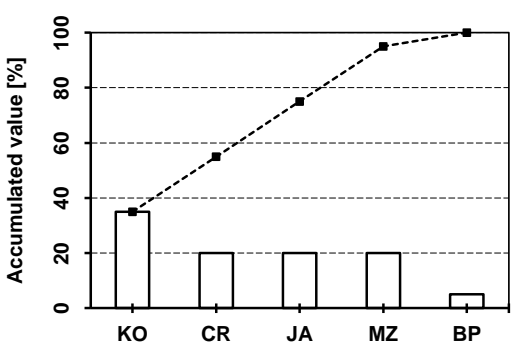

c)

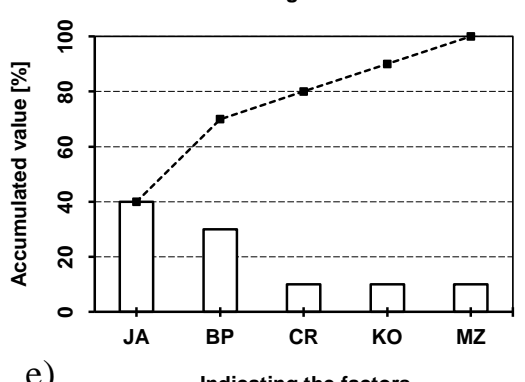

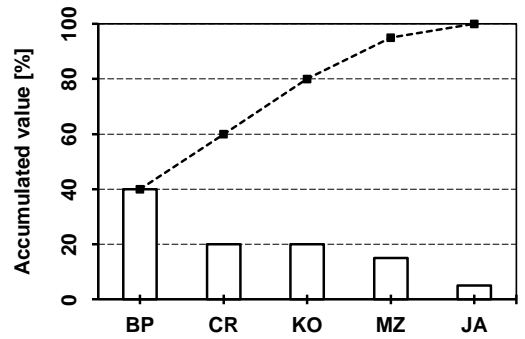

b)

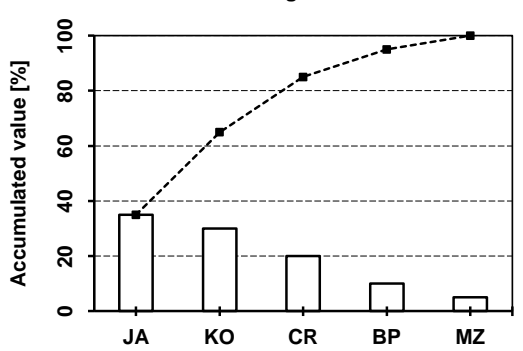

d)

Indicating the factors

Fig. 3. Roof of the Toyota house. Pareto-Lorenz diagrams of the factors' importance E1 area for evaluations: a) „1”, b) „2”, c) „3”, d) „4”, e) „,

On the basis of Fig. 3 was presented importance series of factors for average evaluations. Summing up, a range of important factors in examined enterprise is following:

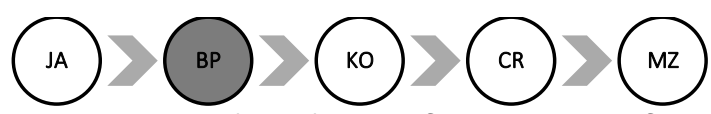

Fig. 4. The importance series of the factors for elements of Toyota's house roof

From analysis of the averages of important factors it results that Safety in the workplace (BP) is a key factor according to respondents (among examined factors it is on the second place in a range of important factors). 


\section{THE RESULTS CONCERNING THE STRUCTURE}

Fig. 5 is presenting box-and-whisker plot and its elements: basic graphs, quartiles Q1, Q2, M - Q1, Q2 - M, length of the upper and bottom plot (Knop and Rosak-Szyrocka, 2016).



a)

Factors indicating
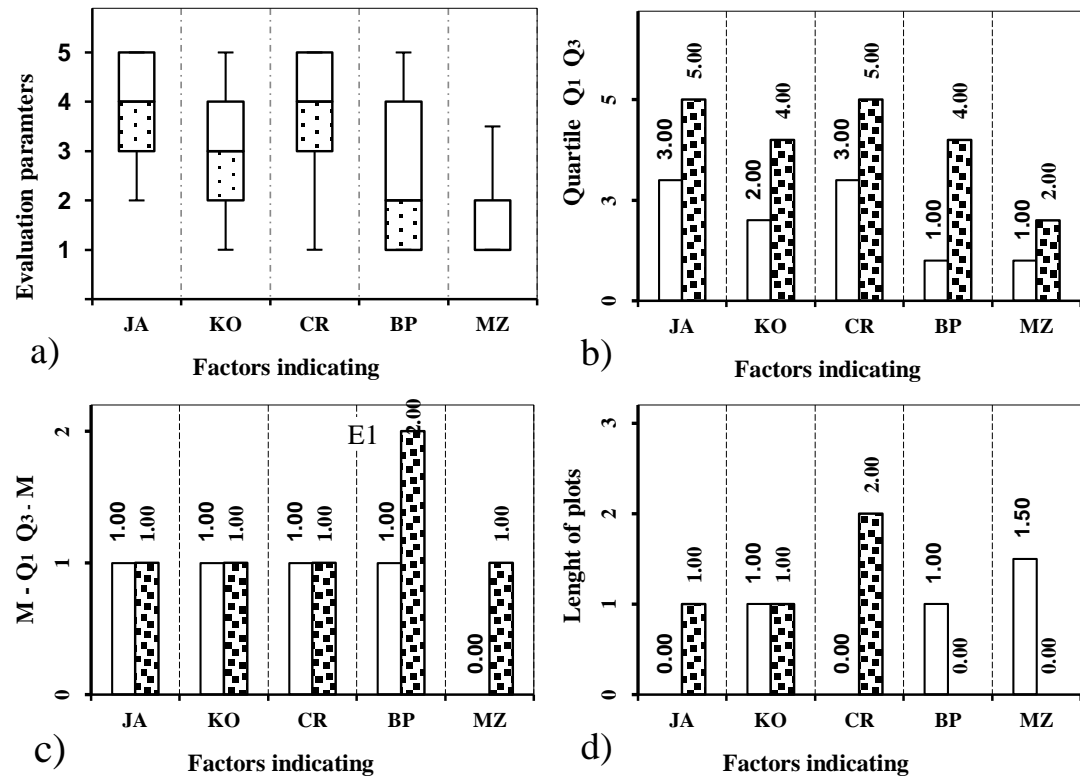

Fig. 5. Elements of the Toyota's house roof. Box-and whisker plots and its elements: a) basic graphs, b) quartiles $Q 1 Q 2$, c) $M-Q 1, Q 2-M$ appropriately, d) length of the plot: upper (without filling), bottom (filled) for factors in E1 area.

Analyzing Fig. 5a we notice that the strongest asymmetry of the disintegration refers to the factor Execution time (CR). Here a strong right-hand asymmetry of the disintegration is appearing. Disintegration of the factor Attitude of the crew (MZ) proves about right-hand skewness, where a positive asymmetry is appearing. Analyzing the disintegration of the factor Cost (KO) we notice that the most symmetrical disintegration of the factor is appearing, the plot is equal length however the box is divided evenly. Analyzing Fig. $5 \mathrm{~b}$ in the case of the factor Quality (JA) and Execution time (CR) the first quartile is 3 , and third quartile 5. For the factor Cost (KO) amounts to the first quartile 4, and third quartile 3. Analyzing the factor Safety in the workplace (BP) we notice that the first quartile is 4 but the third quartile is only 1 . Analyzing Fig. $5 \mathrm{c}$ it is possible to state, that in three cases after subtracting the median from the first quartile the result is 1 , from the third quartile of the median the result is also 1. Analyzing the length of the plot (Fig. $5 \mathrm{~d}$ ) we notice, that in for two factors the Quality (JA) and the Execution time (CR) are not acting as the upper plot, however for three factors the job security, the morale of the crew and the cost are acting as the bottom plot.

\section{SUMMARY}

Innovative BOST questionnaire survey, which are an attempt to convert Toyota's management principles into questions was described. The starting point for changes (improvement) is recording the existing condition. The present situation is definitely known best by participants of the processes implemented in a given enterprise. 
Data obtained from BOST analysis allowed to know the opinions of the representative group of workers in the topic of functioning of the enterprise concerning the competent organization of a production process and its influence on the quality of produced goods. The carried out questionnaire showed that the enterprise had the great potential of filling the meaning position on the market. Functioning of the production system, although now is working perfectly, it is possible still to be improved. The quality of offered products can be improved through applying tools of the quality, or some elements of Kaizen philosophy. How results from the BOST questionnaire survey, that factor Quality (JA) often has been judged with the highest evaluation by respondents. The second position was taken by the factor Safety in the workplace (BP). Studies showed that safety in a range of important factors of the production process took important place, which indicates its significance in the production process in examined enterprises. In the researched company a quality of products, as well as safety in the workplace are important in production process and in the entire company.

\section{REFERENCES}

Amasaka, K., 2012. Science TQM, New Quality Management Principle, The Quality Management Strategy of Toyota Introduction. Bentham Sc. U Arab Emirates.

Borkowski, S. 2016. Scientific Potential of Toyotarity and BOST Method. Polish Quality Institute, Warsaw

Borkowski, S., Jagusiak-Kocik, M., Ingaldi, M., 2014. Evaluation of the Manufacturing of Components for Combine Harvesters Using Bost Method. 23nd International Conference on Metallurgy and Materials METAL, Brno.

Borkowski, S., Rosak-Szyrocka, J., Klimecka-Tatar, D., Jagusiak-Kocik, M., Sygut, P., 2013. Determination of the technology place in the metal company on the basis of the Toyota's management principles. 22nd International Conference on Metallurgy and Materials METAL, Brno.

Gao, S., Low, S.P., 2015. Toyota way style human resource management in large Chinese construction firms. A qualitative study. International Journal of Construction Management, 15(1), 17-32.

Knop, K., 2018. Statistical Control of the Production Process of Rolled Products. Production Engineering Archives 20(2018), 26-31, https://doi.org/ 10.30657/pea.2018.20.06

Knop, K., Mielczarek, K., 2018. Assessment of Production Processes Functioning in the Case of Air Bag Production. MATEC Web Conf. 183, 04009, https://doi.org/ $10.1051 /$ matecconf/201818304009.

Knop, K., Rosak-Szyrocka, J., 2016. Evaluating and improving the effectiveness of the rolling mill in the production of medium steel sections in the selected company from the metallurgical industry. 25th Anniversary International Conference on Metallurgy and Materials, Tanger Ltd., Ostrava, 1869-1875

Liker, J., Franz, J., 2011. The Toyota Way to continuous improvement. McGraw Hill.

Sobek, D.K., Ward, A.C., Liker, J.K., 1999. Toyota's principles of set-based concurrent engineering. Sloan Manage. Rev. 40, 67+.

Ulewicz, R., Selejdak, J., Borkowski, S., Jagusiak-Kocik, M., 2013. Process management in the cast iron foundry, In: METAL 2013 - 22nd International Conference on Metallurgy and Materials, Conference Proceedings, 1926-1931. 